Article

\title{
Astaxanthin Protects Steroidogenesis from Hydrogen Peroxide-Induced Oxidative Stress in Mouse Leydig Cells
}

\author{
Jyun-Yuan Wang ${ }^{1, \dagger}$, Yue-Jia Lee ${ }^{1, \dagger}$, Mei-Chia Chou ${ }^{3}$, Renin Chang ${ }^{4}$, Chih-Hsien Chiu ${ }^{1}$, \\ Yao-Jen Liang ${ }^{2}$ and Leang-Shin $\mathrm{Wu}^{1, *}$
}

1 Department of Animal Science and Technology, College of Bio-Resources and Agriculture, National Taiwan University, Taipei 106, Taiwan; E-Mails: jyunyuanwang@gmail.com (J.-Y.W.); moon7bee@gmail.com (Y.-J.L.); chiuchihhsien@ntu.edu.tw (C.-H.C.)

2 Department and Institute of Life Science, Fu-Jen Catholic University, New Taipei City 242, Taiwan; E-Mail: 071558@mail.fju.edu.tw

3 Department of Physical Medicine and Rehabilitation, Kaohsiung Veterans General Hospital, Pingtung Branch, Pingtung 912, Taiwan; E-Mail: meeichia@yahoo.com.tw

4 Department of Emergency Medicine, Kaohsiung Veterans General Hospital, Kaohsiung 813, Taiwan; E-Mail: rnchang@vghks.gov.tw

$\dagger$ The first two authors contributed equally.

* Author to whom correspondence should be addressed; E-Mail: leshwu@ ntu.edu.tw; Tel.: +886-2-3366-4158; Fax: +886-2-2733-7095.

Academic Editor: Orazio Taglialatela-Scafati

Received: 2 December 2014 / Accepted: 9 February 2015 / Published: 16 March 2015

\begin{abstract}
Androgens, especially testosterone produced in Leydig cells, play an essential role in development of the male reproductive phenotype and fertility. However, testicular oxidative stress may cause a decline in testosterone production. Many antioxidants have been used as reactive oxygen species (ROS) scavengers to eliminate oxidative stress to protect steroidogenesis. Astaxanthin (AST), a natural extract from algae and plants ubiquitous in the marine environment, has been shown to have antioxidant activity in many previous studies. In this study, we treated primary mouse Leydig cells or MA-10 cells with hydrogen peroxide $\left(\mathrm{H}_{2} \mathrm{O}_{2}\right)$ to cause oxidative stress. Testosterone and progesterone production was suppressed and the expression of the mature $(30 \mathrm{kDa})$ form of StAR protein was down-regulated in MA-10 cells by $\mathrm{H}_{2} \mathrm{O}_{2}$ and cAMP co-treatment. However, progesterone production and expression of mature StAR protein were restored in MA-10 cells by a one-hour pretreatment with AST. AST also reduced ROS levels in cells so that
\end{abstract}


they were lower than the levels in untreated controls. These results provide additional evidence of the potential health benefits of AST as a potential food additive to ease oxidative stress.

Keywords: astaxanthin; steroidogenesis; testosterone; oxidative stress; hydrogen peroxide

\section{Introduction}

Androgen plays an essential role in the development of the male reproductive phenotype and fertility. More than $95 \%$ of circulating androgens are derived from the testis while the remainder is primarily produced by the adrenals. The major androgen, testosterone, stimulates the embryo to differentiate into a male before birth, and also regulates fertility, promoting the development of male secondary sexual characteristics after birth [1]. Generally, production of testosterone by testicular Leydig cells is controlled by luteinizing hormone ( $\mathrm{LH})$, a tropic hormone released from the pituitary. Through its $\mathrm{G}$ protein coupled receptor, LH activates adenylyl cyclase by stimulating $\mathrm{G}$ protein and inducing production of the intracellular second messenger cAMP, followed by activation of the PKA pathway and promotion of the expression of key steroidogenic genes. These genes include steroidogenic acute regulatory protein (StAR), which transports cholesterol into mitochondria, and Cypl1al, which cleaves the side chain of cholesterol and catalyzes its conversion into pregnenolone $\left(\mathrm{P}_{5}\right)$. However, the concentration of testosterone in an individual is easily affected by many physiological and biochemical factors. Disturbance of testosterone synthesis or its functions may cause incomplete masculinization before puberty and many reproductive disorders, including poor sperm production, poor sperm quality, azoospermia, cryptorchidism, hypospadias, and even testicular cancer [2].

Oxidative stress is one of the major factors that reduce production of testosterone in Leydig cells. Oxidative stress results from an imbalance between production of reactive oxygen species (ROS) and the scavenging ability of cellular antioxidant defense systems. ROS, including oxygen singlet, superoxide anion $\left(\mathrm{O}_{2} \cdot{ }^{-}\right)$, hydrogen peroxide $\left(\mathrm{H}_{2} \mathrm{O}_{2}\right)$, and hydroxyl radical $\left(\mathrm{OH}^{-}{ }^{-}\right)$, are oxidizing agents. Excessive ROS production may cause DNA damage, protein damage, and lipid peroxidation, which principally alters the membrane structure and function [3]. During a testicular infection, bacterial lipopolysaccharide (LPS)-induced oxidative stress also alters steroidogenesis and spermatogenesis [4]. Multiple studies indicate that ROS alters testosterone production by reducing StAR protein expression and the activity of HSD3B1 and CYP11A1. Because the mitochondria are the critical site for steroid hormone biosynthesis, dissipation of mitochondrial membrane potential caused by ROS also causes down-regulation of testicular testosterone [5-7].

Many antioxidants have been described as ROS scavengers that protect steroidogenesis and/or sperm quality in the testis, avoiding infertility resulting from low testosterone production due to excessive ROS. For example, both ascorbic acid and $\alpha$-tocopherol (Vitamin $\mathrm{C}$ and $\mathrm{E}$ ) can reverse the reduction of testicular testosterone level caused by oxidative damage by rescuing the deficiencies of steroidogenic enzyme activity [8,9]; however, these antioxidants only partially recover the normal level of testosterone. In the present study, by using Leydig cells treated with $\mathrm{H}_{2} \mathrm{O}_{2}$ as a model of oxidative stress, we aim to test the ability of a stronger antioxidant, astaxanthin (AST), to protect steroidogenesis in Leydig cells from damage by oxidative stress. 
AST, a red-orange xanthophyll carotenoid, is a natural extract from algae and plants. AST is ubiquitous in the marine environment and can also be found in animals like crabs, salmon, and shrimp. In addition to being found in a variety of living organisms, research has indicated that AST has many diverse clinical benefits and is high in antioxidant activity [10-12]. As an antioxidant AST quenches free radicals or other oxidants and protects the lipid bilayer from peroxidation with its polar ionic rings and non-polar conjugated carbon-carbon bonds $[13,14]$. Due to its unique chemical structure (Figure 1), the antioxidant property of AST is about 10-fold greater than those of other carotenoids, including lutein, canthaxanthin, and $\beta$ carotene [15]. AST has been approved as a nutraceutical by The United States Food and Drug Administration since 1999. [16]. Now, this antioxidant is available as a commercial nutritional supplement in USA, Sweden, Japan, South Korea, and Taiwan. Due to its safety and outstanding capacity to eliminate free radicals, AST has already become a popular antioxidant added to food and nutritional supplements.

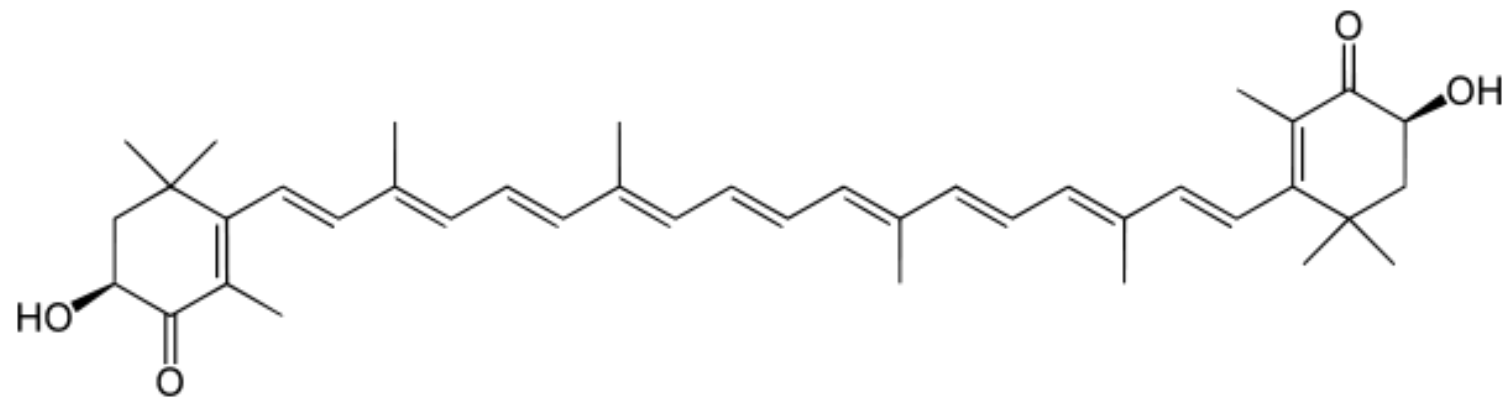

Figure 1. The molecular structure of astaxanthin (AST) is shown.

Because there are many published studies focusing on the effect of AST on maintenance of cellular function under oxidative stress, in the present report we aim to determine whether AST can rescue testosterone production under the oxidative stress caused by $\mathrm{H}_{2} \mathrm{O}_{2}$ and to describe its mechanism of action.

\section{Results}

\subsection{Astaxanthin (AST) Rescues Progesterone and Testosterone Secretion from Testicular Leydig Cells} Reduced by Oxidative Stress

To clarify the potential effects of AST, after pre-treatment with $10 \mu \mathrm{g} / \mathrm{mL}$ AST for $1 \mathrm{~h}$, MA-10 cells were treated with $100 \mu \mathrm{M} 8$-Br-cAMP, $1 \mu \mathrm{g} / \mathrm{mL} 22 \mathrm{R}-\mathrm{OHC}$, or $1 \mu \mathrm{g} / \mathrm{mL}$ pregnenolone to stimulate progesterone production and co-treated with $100 \mu \mathrm{M} \mathrm{H}_{2} \mathrm{O}_{2}$ for an additional $3 \mathrm{~h}$ to establish an oxidative stress while the cells were still being exposed to AST they were co-treated with $100 \mu \mathrm{M} \mathrm{H}_{2} \mathrm{O}_{2}$ for an additional $3 \mathrm{~h}$ to establish an oxidative stress.

Progesterone production in the MA-10 cells was increased by 10-fold after treatment with cAMP $(100 \mu \mathrm{M})$, but only six-fold when co-treated with cAMP and $\mathrm{H}_{2} \mathrm{O}_{2}(19.47 \mathrm{ng} / \mathrm{mL})$, suggesting that $\mathrm{H}_{2} \mathrm{O}_{2}$ suppressed progesterone production. Although AST alone did not promote steroidogenesis, the antioxidant rescued progesterone production supported by cAMP to $25.76 \mathrm{ng} / \mathrm{mL}$ in the presence of $\mathrm{H}_{2} \mathrm{O}_{2}$ (Figure 2A). We also found that even progesterone production supported by exogenous steroidogenic substrates including $22 \mathrm{R}-\mathrm{OHC}$ and pregnenolone was suppressed under the oxidative 
stress induced by $\mathrm{H}_{2} \mathrm{O}_{2}$ treatment. Pretreating cells with AST for an additional $1 \mathrm{~h}$ partially protected the substrate-supported steroidogenesis in MA-10 cells under oxidative stress (Figure 2B,C).
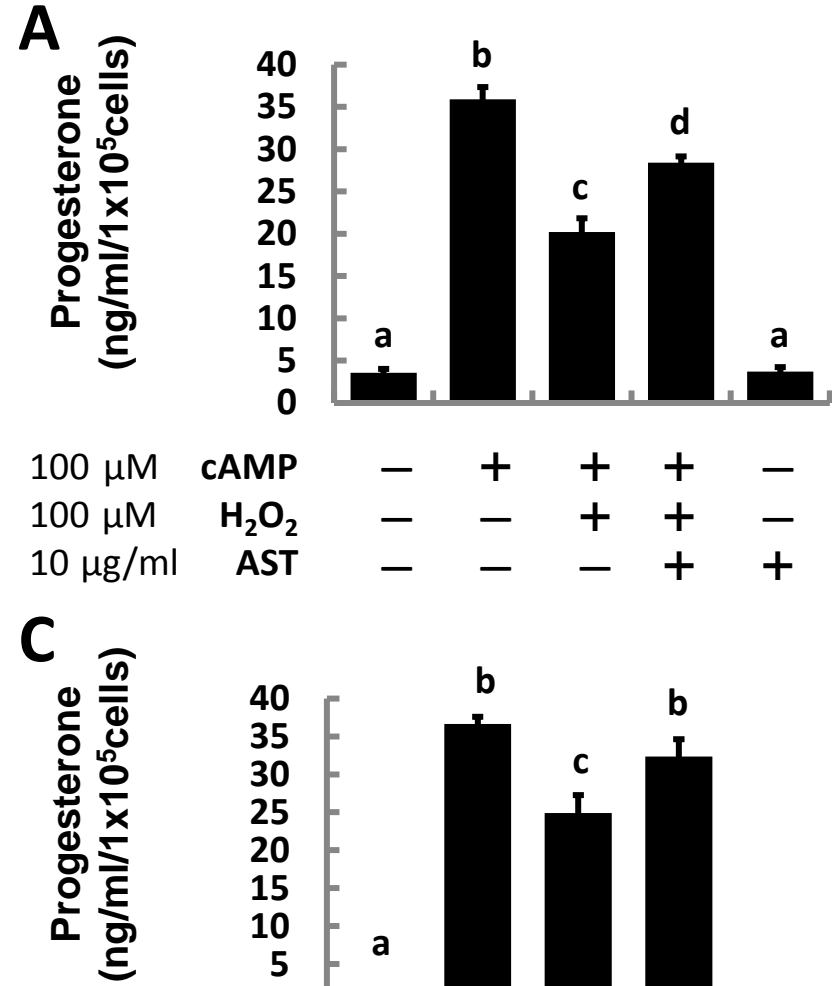

$1 \mu \mathrm{g} / \mathrm{ml}$
$100 \mu \mathrm{M}$
$10 \mu \mathrm{g} / \mathrm{ml}$
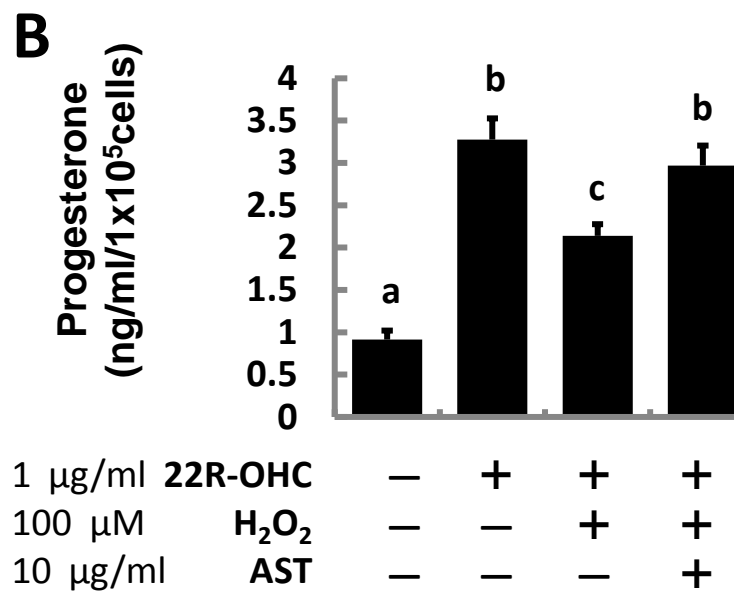

Figure 2. Astaxanthin (AST) restored progesterone production in MA-10 cells induced by cAMP and steroid precursors (22R-OHC, pregnenolone) inhibited by hydrogen peroxide. Cells exposed to AST for $1 \mathrm{~h}$ and untreated controls were challenged with $100 \mu \mathrm{M}$ hydrogen peroxide and (A) $100 \mu \mathrm{M}$ Camp; (B) $1 \mu \mathrm{g} / \mathrm{mL} 22 \mathrm{R}-\mathrm{OHC}$; or (C) $1 \mu \mathrm{g} / \mathrm{mL}$ pregnenolone $\left(\mathrm{P}_{5}\right)$ for additional $3 \mathrm{~h}(n=3)$. Data were shown as mean with SEM. Bars labeled with different letters $(\mathrm{a}-\mathrm{d})$ are significantly different $(p<0.05)$ from each other.

To corroborate our previous results, we examined the effect of AST on testosterone production in primary Leydig cells isolated from adult mouse testes. Similar to the results in the MA-10 cell experiment, cAMP-induced testosterone production $(0.77 \mathrm{ng} / \mathrm{mL})$ was roughly five-fold greater than that of the vehicle group $(0.15 \mathrm{ng} / \mathrm{mL})$; whereas, the induced production was significantly decreased after cells were co-treated with $\mathrm{H}_{2} \mathrm{O}_{2}(0.56 \mathrm{ng} / \mathrm{mL})$. However, pre-treatment with AST kept testosterone production $(0.75 \mathrm{ng} / \mathrm{mL})$ at the same level as the cAMP-treated group (Figure 3).

These results suggest that AST supplementation could rescue lost progesterone production resulting from the addition of $\mathrm{H}_{2} \mathrm{O}_{2}$ in both a Leydig cell line and primary mouse Leydig cells. 


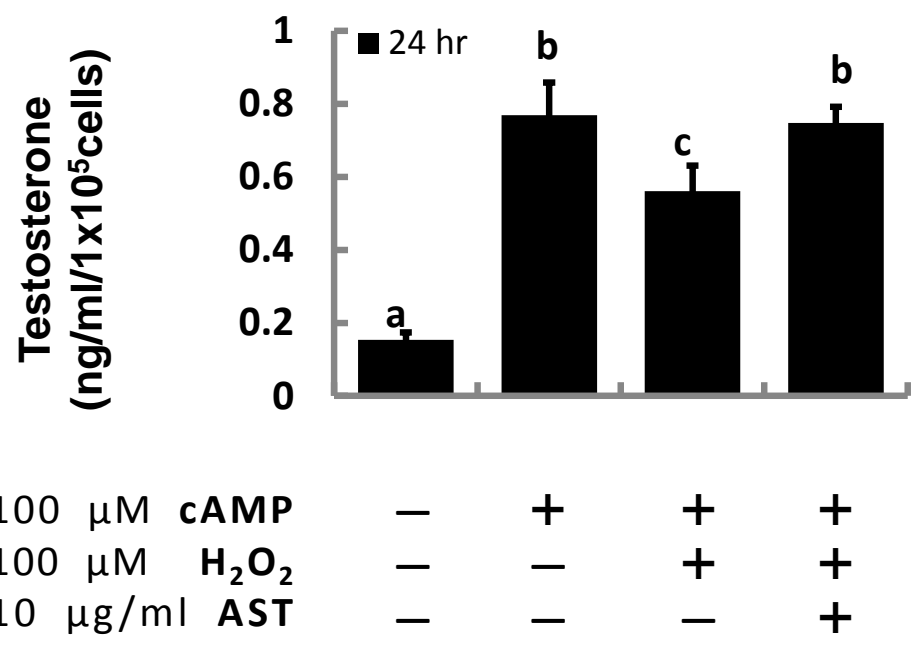

Figure 3. Astaxanthin (AST) rescued the increased testosterone production in primary Leydig cells induced by cAMP impaired by hydrogen peroxide. Cells exposed to AST for $1 \mathrm{~h}$ or untreated controls were challenged with $100 \mu \mathrm{M}$ cAMP, $100 \mu \mathrm{M}$ hydrogen peroxide, or both for an additional $23 \mathrm{~h}(n=3)$. Data were shown as mean with SEM. Bars labeled with different letters $(\mathrm{a}-\mathrm{c})$ are significantly different $(p<0.05)$ from each other.

\subsection{AST Reduced ROS Levels in MA-10 Leydig Cells}

Previous results indicated that steroidogenesis in MA-10 cells is protected by AST under oxidative stress induced by $\mathrm{H}_{2} \mathrm{O}_{2}$. To determine if the effect of AST on steroidogenesis is through scavenging elevated ROS within the cells 2',7'-dichlorodihydrofluorescein diacetate (DCFH-DA), a probe that converts into the highly fluorescent 2',7'-dichlorofluorescein (DCF) after being oxidized by ROS, was used to analyze ROS levels in MA-10 Leydig cells.

After treatment with 8-Br-cAMP, 22R-OHC, or pregnenolone MA-10 cells were stained with $10 \mu \mathrm{M}$ DCFH-DA for $30 \mathrm{~min}$ followed by $10 \mu \mathrm{g} / \mathrm{mL}$ Hoechst for $1 \mathrm{~min}$. Exposure to cAMP did not increase the fluorescence intensity compared to controls; however, co-treatment of cAMP and $\mathrm{H}_{2} \mathrm{O}_{2}$ significantly elevated the ROS level in MA-10 cells. Administration of AST $1 \mathrm{~h}$ before cAMP and $\mathrm{H}_{2} \mathrm{O}_{2}$ co-treatment could vigorously eliminate ROS in cells, described as reduced green fluorescence intensity as shown in the right column of Figure 4A. The fluorescence microscopy findings were quantified (Figure 4B) and the relative ROS production in the cells is represented as the ratio of fluorescence of DCF and Hoechst staining. Because ROS production only increased by $20 \%$ in cAMP-treated cells, ROS level rose to over two-fold production of the control group due to addition of $\mathrm{H}_{2} \mathrm{O}_{2}$. Nevertheless, ROS production in the cells pre-treated with AST was the same as that in the cells treated with only cAMP. Briefly, both the fluorescence images and statistical data confirmed that AST could scavenge ROS in the cells under oxidative stress. We postulate that attenuating the production of ROS or eliminating ROS may be possible mechanisms involved in the protection of steroidogenesis by AST. 

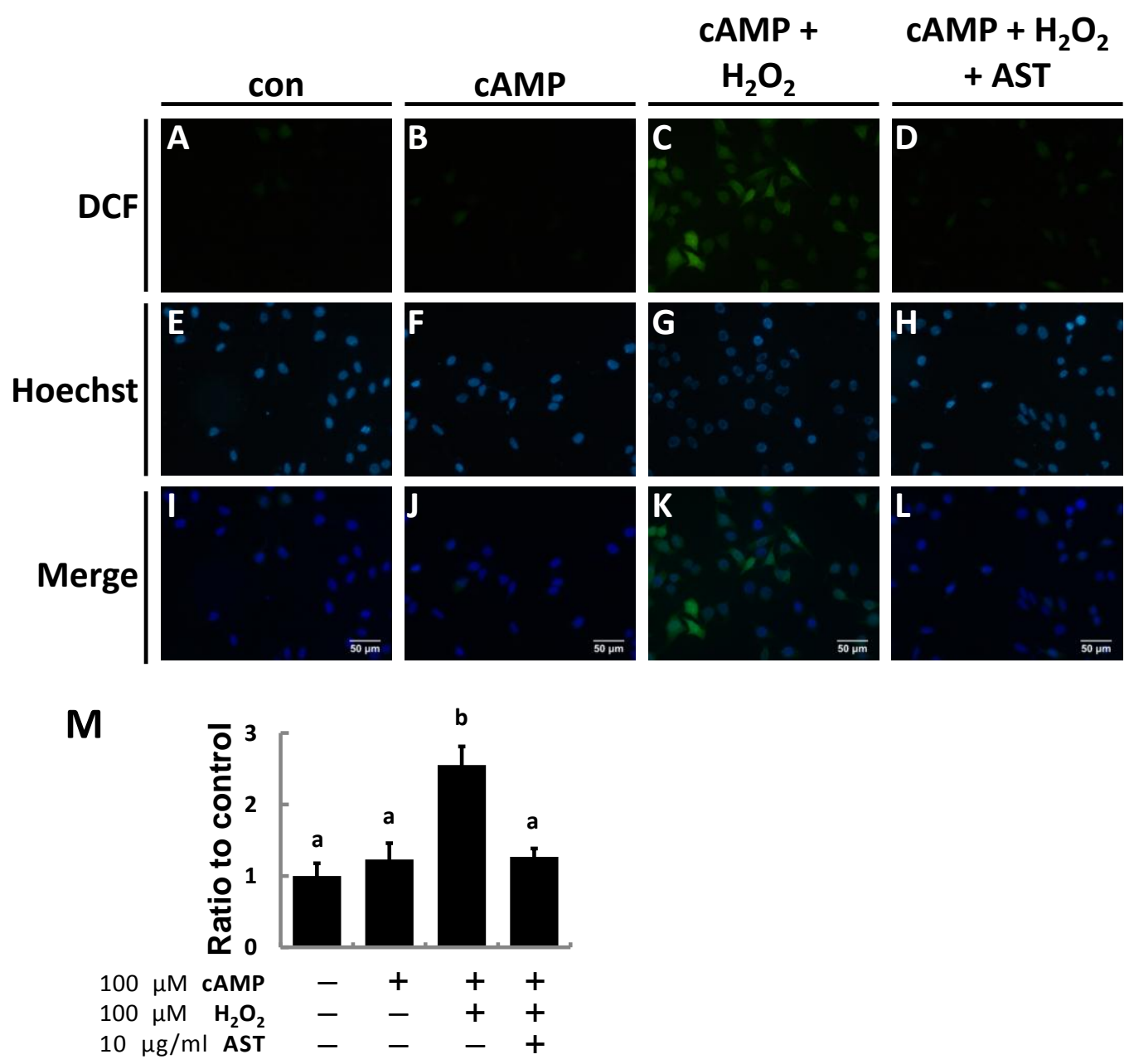

Figure 4. Astaxanthin (AST) protects MA-10 Leydig cells from peroxide-induced ROS. After treatments, cells were incubated in the medium containing $10 \mu \mathrm{M}$ DCFH-Da for 30 min following a one-minute incubation with $10 \mu \mathrm{g} / \mathrm{mL}$ Hoechst. (A-L) Treated cells on the slides were visualized using fluorescence microscopy. Images from top to bottom display produced ROS (green), nuclei (blue), and a merged image of the previous two; (M) DCF/Hoechst fluorescence was analyzed by microplate fluorometry using excitation and emission wavelengths of 485 (355) $\mathrm{nm}$ and 530 (465) $\mathrm{nm}$, respectively. Data were shown as mean with SEM. Bars labeled with different letters $(a, b)$ are significantly different $(p<0.05, n=3)$ from each other.

\subsection{AST Protects the Expression Level of Steroidogenic Proteins (StAR, P450scc, and 3 $\beta$-HSD) in MA-10 Leydig Cells during Oxidative Stress}

Finally, MA-10 cells were treated with cAMP and $\mathrm{H}_{2} \mathrm{O}_{2}$ for $3 \mathrm{~h}$ or treated with AST for $4 \mathrm{~h}$ with co-treatment with cAMP and $\mathrm{H}_{2} \mathrm{O}_{2}$ during the last $3 \mathrm{~h}$ to evaluate the effect of $\mathrm{H}_{2} \mathrm{O}_{2}$ and AST on steroidogenic protein expression. After treatment, only the expression of the $30 \mathrm{kDa}$ isoform of StAR protein was significantly induced by cAMP (1.8-fold higher than controls), and the increased expression level was totally eliminated by $\mathrm{H}_{2} \mathrm{O}_{2}$. However, with pre-treatment by AST, the expression level of StAR didn't obviously decrease (Figure 5B). In contrast, neither P450scc nor 3 $\beta$-HSD was significantly regulated by cAMP, $\mathrm{H}_{2} \mathrm{O}_{2}$, or AST (Figure 5C,D). 
A

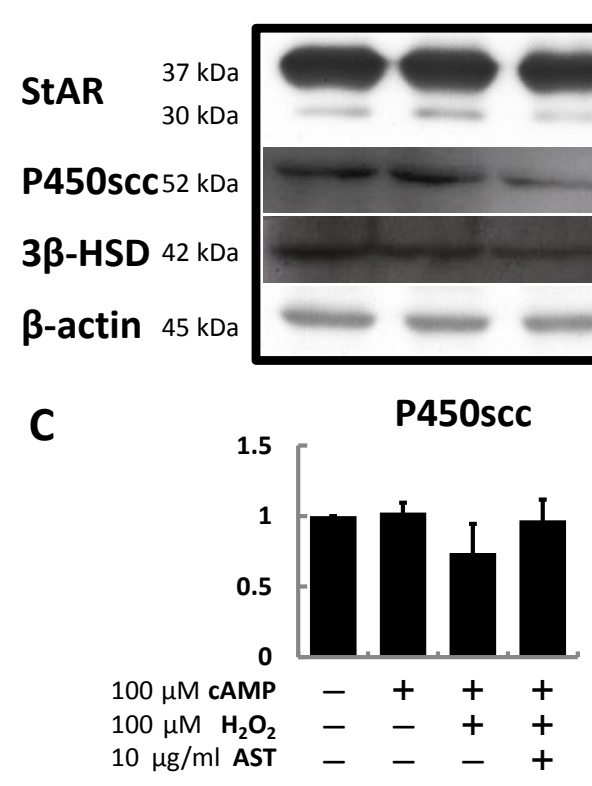

B

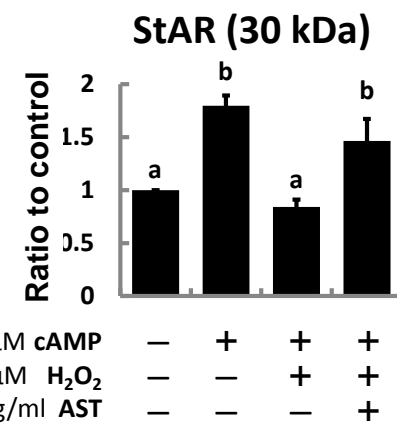

D

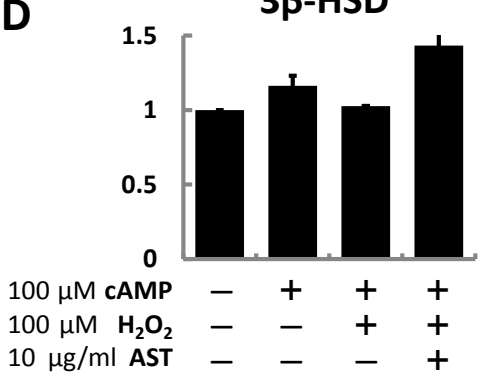

Figure 5. Astaxanthin restores the expression of steroidogenic proteins (StAR, P450scc, and 3 $\beta$-HSD) in MA-10 cells inhibited by peroxide. (A) Representative western blot analysis of MA-10 cells for StAR, P450scc, 3 $\beta$-HSD proteins, and $\beta$-actin loading controls ( $30 \mu \mathrm{g}$ of total protein/lane). The relative values (ratio to $\beta$-actin) of (B) $30 \mathrm{kDa} \mathrm{StAR;} \mathrm{(C)} \mathrm{P450scc;}$ and (D) $3 \beta$-HSD were quantified by densitometric analysis $(n=3)$. Data were shown as mean with SEM. Different symbols $(a, b)$ indicate a significant difference $(p<0.05)$ from each other.

\section{Discussion}

Over the past several decades, numerous studies have described the biological functions and clinical benefits of AST [17], especially in protection against oxidation by ROS [10,18,19]. Because of its antioxidant ability and other beneficial functions, the United States Food and Drug Administration approved AST as a nutraceutical in 1999 [16]. Recently, AST has been described to improve sperm quality and function during redox system imbalance [20]. Moreover, Comhaire and his colleagues found that AST decreases ROS and the secretion of inhibin B by Sertoli cells, also enhancing the pregnancy rate in a double-blind randomized trial [21]. Thus, further exploration whether AST also protects the endocrine system required for reproductive behavior and production of normal fertile testicular spermatozoa may be worthwhile.

Steroid hormones are synthesized through steroidogenesis in the cells of the adrenal cortex and the gonads (testis and ovary). Steroidogenesis in the testis and ovary are mainly regulated by LH; whereas, this process is controlled by ACTH, a tropic hormone released from anterior pituitary, in the adrenal [22]. LH and ACTH bind to their membrane-bound G protein-coupled receptors and signal by activating the cAMP/PKA pathway, the major signaling pathway regulating steroid biosynthesis [23].

Hydrogen peroxide has a negative effect on steroidogenesis. In vivo generation of hydrogen peroxide occurs during luteolysis in the superovulated rat in response to prostaglandin F2 $\alpha$ secretion from the rat corpus luteum [24]. Under hydrogen peroxide treatment estradiol and progesterone secretion are inhibited in human luteal cells [25]. The acute blockade of steroidogenesis may be due to uncoupling of 
LH receptor and adenylyl cyclase [26] and the effect of suppressed expression of CYP11A1 on cholesterol utilization [27]. Furthermore, LDL uptake by the porcine luteal cell is inhibited by hydrogen peroxide [28]. Oxidative stress induced by hydrogen peroxide, 4-hydroxy-2-nonenal (HNE), or thiobaribituric acid-reactive substances (TBARS) also suppresses steroid hormone production in adrenal cells by activating the p38 MAPK pathway [29,30]. Hydrogen peroxide suppresses steroidogenesis in MA-10 cells [6,31], and hydrogen peroxide decreases the mature form of StAR protein but not its mRNA expression [5,7]. Oxidative damage caused by hydrogen peroxide not only reduces the expression level of StAR protein, but also disrupts mitochondrial membrane potential $(\Delta \Psi \mathrm{m})$ [7]. In the mouse Leydig cell line $\mathrm{K} 28 \mathrm{JNK}$ is responsible for the suppression of CYP17A1 expression by decreasing the transcriptional activity of NR4A1 [32].

In the present study, progesterone production in MA-10 cells is significantly increased by 10-fold after cells are treated with 8-Br-cAMP. However, this elevated production of progesterone is reduced by half when the cells are co-treated with cAMP and hydrogen peroxide, similar to previous studies. Co-treatment with AST diminishes the effect of hydrogen peroxide and restores steroidogenesis. The same effect can be seen when MA-10 cells are treated with 22-hydroxycholesterol or pregnenolone, in which hydrogen peroxide also suppresses progesterone production supported by these two steroid substrates.

Not only can hydrogen peroxide suppress progesterone production in the immortalized MA-10 Leydig cell-like line, but also in primary mouse Leydig cells. Treatment of primary rat Leydig cells with polychlornated biphenyls (PCBs) promotes ROS formation and reduces the activity of enzymes necessary for testosterone production [33]. A similar effect can be seen in this study since 22R-hydroxycholesterol is catalyzed into progesterone by the activity of CYP11A1 and HSD3B1 while pregnenolone is converted into progesterone by HSD3B1. Inhibition of progesterone production demonstrates that the enzymatic activities of CYP11A1 and HSD3B1 are inhibited under oxidative stress.

To prove that hydrogen peroxide enhances ROS production in MA-10 cells, DCFH-Da was used to indicate intracellular ROS level. Based on our results, cAMP does not significantly alter the cellular ROS level. As expected, hydrogen peroxide increases the ROS level while co-treatment with AST attenuates the ROS level in MA-10 cells. These results clearly demonstrate that AST can be a scavenger of ROS, can decrease oxidative stress on MA-10 cells, and can also restore steroidogenesis in these cells.

Finally, since hydrogen peroxide attenuates the post-cAMP pathway, mRNA or protein expression of steroidogenic genes may be altered under by this treatment. The expression of the mature form of StAR $(30 \mathrm{kDa})$ was decreased by hydrogen peroxide treatment, but was restored after co-treatment with AST.

\section{Experimental Section}

\subsection{Reagents and Chemicals}

Cell culture medium DMEM/F12 and medium 199, trypsin-EDTA (0.25\%), penicillin G, streptomycin sulfate, fetal bovine serum (FBS), Hank's balanced salt solution (HBSS), and trypan blue stain were purchased from Invitrogen Corporation (Grand Island, NY, USA). Collagenase type 1 was purchased from Worthington Biochemical Corporation (Lakewood, NJ, USA). Bovine serum albumin (BSA) and other general chemicals were purchased from Sigma-Aldrich (St. Louis, MO, USA), and 8-bromocyclic AMP was purchased from Tocris Bioscience (Ellisville, MO, USA). Pregnenolone was purchased 
from Steraloids, Inc. (Newport, RI, USA) and 22-hydroxycholesterol (22ROHC) was purchased from Sigma-Aldrich.

\subsection{Primary Mouse Leydig Cell Culture}

Male C57BL/6 mice (5-week-old) were purchased from National Taiwan University, maintained under 12-h light (0900-2100)/12-h dark (2100-0900) conditions, and allowed free access to chow and water. All mice were retained until 10-weeks-old before isolating primary Leydig cells. All experimental protocols were approved by the Animal Care and Use Committee in the College of Medicine, National Taiwan University. All procedures conformed to the National Institutes of Health Guide for the care and use of laboratory animals. After mice were sacrificed by decapitation, the testes were removed and decapsulated in medium 199 supplemented with 10\% serum. Then, the seminiferous tubules were separated, washed once with isolation buffer $(10 \mathrm{~mL}$ HBSS containing $0.1 \%$ BSA and $200 \mathrm{U} / \mathrm{mL}$ collagenase type 1), and incubated at room temperature in isolation buffer for an additional $5 \mathrm{~min}$. The seminiferous tubules and cells were filtered through a 250 micron mesh, and then the cells were collected by centrifugation at $300 \times g$ for $5 \mathrm{~min}$ and resuspended in $10 \mathrm{~mL}$ of medium 199 without supplemental serum. Live cells were counted with trypan blue stain, and then seeded $\left(10^{6}\right.$ cells per $\left.\mathrm{mL}\right)$ in culture tubes (Corning Inc, Oneonta, NY, USA). Cells were immediately treated with different doses of cAMP, $\mathrm{H}_{2} \mathrm{O}_{2}$ and AST and incubated at $37{ }^{\circ} \mathrm{C}$ with $5 \% \mathrm{CO}_{2}$. After $4 \mathrm{~h}$, the culture medium was collected and stored at $-20{ }^{\circ} \mathrm{C}$ until the enzyme immunoassay (EIA) was performed.

\subsection{Culture of MA-10 Cells}

MA-10 mouse Leydig tumor cells were seeded into T-75 cell culture flasks (Thermo Scintific, West Palm Beach, FL, USA) with DMEM/F-12 medium, supplemented with 10\% FBS, $2.2 \mathrm{mg} / \mathrm{mL}$ sodium bicarbonate, $100 \mathrm{U} / \mathrm{mL}$ penicillin, and $0.1 \mathrm{mg} / \mathrm{mL}$ streptomycin and incubated at $37{ }^{\circ} \mathrm{C}$ with $5 \% \mathrm{CO}_{2}$. Before experiments, nonadherent cells were removed by aspiration, and healthy cells were collected by trypsinization and centrifugation. The cell pellets were gently resuspended in DMEM/F-12 medium without FBS, and cells were seeded into 48 -well plates $\left(5 \times 10^{4}\right.$ cells/well), after incubation overnight, medium was changed and all cell treated with different chemicals, and incubated at $37{ }^{\circ} \mathrm{C}$ with $5 \% \mathrm{CO}_{2}$. After treatment, the culture medium was collected and stored at $-20^{\circ} \mathrm{C}$ until EIA was performed.

\subsection{Enzyme Immunoassay for Progesterone and Testosterone}

The progesterone assay was modified from a direct EIA using G7, an IgM monoclonal antibody with specific affinity of $1.1 \times 10^{10} \mathrm{M}$, as described previously [34-36]. G7 exhibits cross-reactivity of $<0.01 \%$ with BSA and other steroids including pregnenolone, testosterone, estradiol, and estrone. Aliquots $(50 \mu \mathrm{L})$ of diluted medium and horseradish peroxide-linked progesterone conjugate $(150 \mu \mathrm{L})$ were added to microtiter plates coated with $200 \mu \mathrm{L} \mathrm{G7}$ (representing a 1:40,000 dilution). After a 15-min incubation at room temperature with gentle shaking and two washes with Tween-20 in $0.01 \mathrm{M}$ phosphate buffer ( $\mathrm{pH} 7.0$ ), the color was developed with $3.7 \mathrm{mM} \mathrm{O}$-phenylenediamine $(200 \mu \mathrm{L})$ in $0.03 \% \mathrm{H}_{2} \mathrm{O}_{2}$ for an additional $15 \mathrm{~min}$. The reaction was stopped by adding $8 \mathrm{~N} \mathrm{H}_{2} \mathrm{SO}_{4}(50 \mu \mathrm{L})$. The optical density (OD) of each sample was determined with $\mu$ Quant EIA reader (BioTek, Winooski, VT, USA) set wavelength 
of absorption between 490 and $630 \mathrm{~nm}$. Progesterone concentration was determined with a standard curve. Coefficients of variation were $7 \%$ (within assays) and 12\% (between assays). The sensitivity of the assay was $0.3 \mathrm{pg} / \mathrm{mL}$ [35]. All standards and samples were assayed in duplicate.

\subsection{Staining of Intracellular ROS of MA-10 Cells}

Method of ROS staining was modified from previous study [37]. Briefly, MA-10 cells were seeded on round cover slides, which were put in a 24-well cultured plate. After treated with AST, cAMP and $\mathrm{H}_{2} \mathrm{O}_{2}$, medium were removed and cells were washed once with DMEM/F12 medium without serum then incubated in medium containing $10 \mu \mathrm{M}$ 2',7'-dichlorodihydrofluorescein diacetate (DCFH-DA) for $30 \mathrm{~min}$ following $1 \mathrm{~min}$ incubation with $10 \mu \mathrm{g} / \mathrm{mL}$ Hoechst 33342. After treatment, cover slides were removed from 24-well dish and washed with PBS and cover on a glass slide for fluorescent microscope observation (Olympus IX-70 with fluorescent facility). Images were captured with camera (Olympus E-330, Olympus, Shinjuku, Japan). For quantitative assay, MA-10 cells were seeded in black 96-well plate. After treated with AST, cAMP, $\mathrm{H}_{2} \mathrm{O}_{2}$ and stained with DCFH-DA and Hoechst 33342, plate was read with microplate reader Synergy H1 (BioTek) with excitation of $485 \mathrm{~nm}$, emission of $530 \mathrm{~nm}$ for DCF and excitation of $355 \mathrm{~nm}$, emission of $465 \mathrm{~nm}$ for Hoechst 33342.

\subsection{Western Blot Analysis}

After treatment, the cells were rinsed twice with cold phosphate-buffered saline (PBS) and harvested. Then the cells were resuspended in cold lysis buffer (2\% SDS, 50mM Tris (pH 6.8), 5mM EDTA, 1\% 2-mercaptoethanol, 5\% glycerol), and whole-cell extracts were prepared, as described previously [38]. Samples containing $40 \mu \mathrm{g}$ protein were separated by $12 \%$ SDS-polyacrylamide gel electrophoresis, as described previously [38]. The separated proteins were transferred to a polyvinylidene fluoride membrane. The membrane was blocked by incubating in PBS containing 0.01\% Tween-20 (PBST) and $2.5 \% \mathrm{BSA}$ for $8 \mathrm{~h}$ at room temperature, followed by incubation with rabbit polyclonal primary antibodies specific for StAR (1:10,000 dilution) [36,39], CYP11A1 (1:5000 dilution), HSD3B1 (1:10,000 dilution) [36,40], and ACTB (1:5000 dilution) (MAB1501, Millipore, Temecula, CA, USA) in PBST overnight at $4{ }^{\circ} \mathrm{C}$. After four washes with PBST, the membrane was incubated for $2 \mathrm{~h}$ with peroxidase conjugated goat anti-rabbit IgG (1:7000 dilution; Jackson ImmunoResearch, West Grove, PA, USA). The membranes were washed with PBST, and bound antibodies were visualized by the ECL system (Millipore) using Kodak X-OMAT film (Eastman Kodak Co., Rochester, NY, USA).

\subsection{Data Analysis}

Western blot experiments were performed three times, and a representative result is shown. Densities of blots were quantified with VisionWorksLS Image Acquisition and Analysis Software (UVP, Upland, CA, USA). Results are presented as multiple of control. Results are expressed as mean with standard error of the mean (SEM) of triplicate samples from three individual experiments. Western blot data were analyzed with Student's $t$-test using Microsoft Excel 2007. Results of other assays were analyzed by one-way ANOVA followed by Duncan's multiple comparison using SigmaStat 12 (Aspire Software International, Ashburn, VA, USA). $p<0.05$ was considered significant. 


\section{Conclusions}

To our knowledge, this is the first study to demonstrate that AST can protect steroidogenesis in Leydig cells from oxidative stress. Hydrogen peroxide can induce oxidative stress and attenuate the post-PKA pathway resulting in suppressed expression of the mature form of StAR protein. However, by reducing ROS formation caused by hydrogen peroxide, AST prevents the down-regulation of the mature form of the StAR protein, and restores steroidogenesis in the Leydig cell.

\section{Acknowledgments}

This research was supported by Grant from the Ministry of Science and Technology, Republic of China (MOST102-2313-B-002-025).

\section{Author Contributions}

Jyun-Yuan Wang wrote the manuscript and designed some experiments in this study, Yue-Jia Lee designed the remaining experiments while performed all experiments in this study also joined the writing of this manuscript. Mei-Chia Chou and Renin Chang analyzed the data. Chih-Hsien Chiu and Yao-Jen Liang provided reagents and materials used in this study and Leang-Shin Wu conceived the experiments.

\section{Conflicts of Interest}

The authors declare no conflict of interest.

\section{References}

1. Ge, R.; Hardy, M. Regulation of Leydig Cells During Pubertal Development. In The Leydig Cell in Health and Disease; Humana Press: Totowa, NJ, USA, 2007; pp. 55-70.

2. Svechnikov, K.; Izzo, G.; Landreh, L.; Weisser, J.; Soder, O. Endocrine disruptors and Leydig cell function. J. Biomed. Biotechnol. 2010, 2010, 684504, doi:10.1155/2010/684504.

3. Giorgio, M.; Trinei, M.; Migliaccio, E.; Pelicci, P.G. Hydrogen peroxide: A metabolic by-product or a common mediator of ageing signals? Nat. Rev. Mol. Cell Biol. 2007, 8, 722-728.

4. Reddy, M.M.; Mahipal, S.V.; Subhashini, J. Reddy, M.C.; Roy, K.R.; Reddy, G.V.; Reddy, P.R.; Reddanna, P. Bacterial lipopolysaccharide-induced oxidative stress in the impairment of steroidogenesis and spermatogenesis in rats. Reprod. Toxicol. 2006, 22, 493-500.

5. Diemer, T.; Allen, J.A.; Hales, K.H.; Hales, D.B. Reactive oxygen disrupts mitochondria in MA-10 tumor Leydig cells and inhibits steroidogenic acute regulatory (StAR) protein and steroidogenesis. Endocrinology 2003, 144, 2882-2891.

6. Tsai, S.C.; Lu, C.C.; Lin, C.S.; Wang, P.S. Antisteroidogenic actions of hydrogen peroxide on rat Leydig cells. J. Cell. Biochem. 2003, 90, 1276-1286.

7. Hales, D.B.; Allen, J.A.; Shankara, T.; Janus, P.; Buck, S.; Diemer. T.; Hales, K.H. Mitochondrial function in Leydig cell steroidogenesis. Ann. N. Y. Acad. Sci. 2005, 1061, 120-134. 
8. Murugesan, P.; Muthusamy, T.; Balasubramanian, K.; Arunakaran, J. Studies on the protective role of vitamin $\mathrm{C}$ and $\mathrm{E}$ against polychlorinated biphenyl (Aroclor 1254)—Induced oxidative damage in Leydig cells. Free Radic. Res. 2005, 39, 1259-1272.

9. Chang, S.I.; Jin, B.; Youn, P.; Park, C.; Park, J.D.; Ryu, D.Y. Arsenic-induced toxicity and the protective role of ascorbic acid in mouse testis. Toxicol. Appl. Pharmacol. 2007, 218, 196-203.

10. Lu, Y.P.; Liu, S.Y.; Sun, H.; Wu, X.M.; Li, J.J.; Zhu, L. Neuroprotective effect of astaxanthin on $\mathrm{H}_{2} \mathrm{O}_{2}$-induced neurotoxicity in vitro and on focal cerebral ischemia in vivo. Brain Res. 2010, 1360, $40-48$.

11. Lee, D.H.; Kim, C.S.; Lee, Y.J. Astaxanthin protects against MPTP/MPP+-induced mitochondrial dysfunction and ROS production in vivo and in vitro. Food Chem. Toxicol. 2011, 49, 271-280.

12. Wolf, A.M.; Asoh, S.; Hiranuma, H.; Ohsawa, I.; Iio, K.; Satou, A.; Ishikura, M.; Ohta, S. Astaxanthin protects mitochondrial redox state and functional integrity against oxidative stress. J. Nutr. Biochem. 2010, 21, 381-389.

13. Hussein, G.; Sankawa, U.; Goto, H.; Matsumoto, K.; Watanabe, H. Astaxanthin, a carotenoid with potential in human health and nutrition. J. Nat. Prod. 2006, 69, 443-449.

14. Ranga Rao, A.; Raghunath Reddy, R.L.; Baskaran, V.; Sarada, R.; Ravishankar, G.A. Characterization of microalgal carotenoids by mass spectrometry and their bioavailability and antioxidant properties elucidated in rat model. J. Agric. Food Chem. 2010, 58, 8553-8559.

15. Wiki, W. Biological functions and activities of animal carotenoids. Pure Appl. Chem. 1991, 63, 141-161.

16. Guerin, M.; Huntley, M.E.; Olaizola, M.; Haematococcus astaxanthin: Applications for human health and nutrition. Trends Biotechnol. 2003, 21, 210-216.

17. Yuan, J.P.; Peng, J.; Yin, K.; Wang, J.H. Potential health-promoting effects of astaxanthin: A high-value carotenoid mostly from microalgae. Mol. Nutr. Food Res. 2011, 55, 150-165.

18. Bolin, A.P.; Macedo, R.C.; Marin, D.P.; Barros, M.P.; Otton, R. Astaxanthin prevents in vitro auto-oxidative injury in human lymphocytes. Cell Biol. Toxicol. 2010, 26, 457-467.

19. Fassett, R.G.; Coombes, J.S. Astaxanthin in cardiovascular health and disease. Molecules 2012, 17, 2030-2048.

20. Tripathi, D.N.; Jena, G.B. Astaxanthin inhibits cytotoxic and genotoxic effects of cyclophosphamide in mice germ cells. Toxicology 2008, 248, 96-103.

21. Comhaire, F.H.; El Garem, Y.; Mahmoud, A.; Eertmans, F.; Schoonjans, F. Combined conventional/antioxidant "Astaxanthin" treatment for male infertility: A double blind, randomized trial. Asian J. Androl. 2005, 7, 257-262.

22. Dufau, M.L. The luteinizing hormone receptor. Annu. Rev. Physiol. 1998, 60, 461-496.

23. Hansson, V.; Skalhegg, B.S.; Tasken, K. Cyclic-AMP-dependent protein kinase (PKA) in testicular cells. Cell specific expression, differential regulation and targeting of subunits of PKA. J. Steroid Biochem. Mol. Biol. 1999, 69, 367-378.

24. Riley, J.C.; Behrman, H.R. In vivo generation of hydrogen peroxide in the rat corpus luteum during luteolysis. Endocrinology 1991, 128, 1749-1753. 
25. Vega, M.; Carrasco, I.; Castillo, T.; Troncoso, J.L.; Videla, L.A.; Devoto, L. Functional luteolysis in response to hydrogen peroxide in human luteal cells. J. Endocrinol. 1995, 147, 177-182.

26. Behrman, H.R.; Aten, R.F. Evidence that hydrogen peroxide blocks hormone-sensitive cholesterol transport into mitochondria of rat luteal cells. Endocrinology 1991, 128, 2958-2966.

27. Musicki, B.; Aten, R.F.; Behrman, H.R. Inhibition of protein synthesis and hormone-sensitive steroidogenesis in response to hydrogen peroxide in rat luteal cells. Endocrinology 1994, 134, 588-595.

28. Brannian, J.D.; Larson, E.A.; Kurz, S.G.; Chaput, G.M. Hydrogen peroxide suppresses low-density lipoprotein (LDL) uptake and LDL-supported steroidogenesis by porcine luteal cells. Mol. Cell Endocrinol. 1995, 111, 213-218.

29. Abidi, P.; Zhang, H.; Zaidi, S.M.; Shen, W.J.; Leers-Sucheta, S.; Cortez, Y.; Han, J.; Azhar, S. Oxidative stress-induced inhibition of adrenal steroidogenesis requires participation of $\mathrm{p} 38$ mitogen-activated protein kinase signaling pathway. J. Endocrinol. 2008, 198, 193-207.

30. Abidi, P.; Leers-Sucheta, S.; Cortez, Y.; Han, J.; Azhar, S. Evidence that age-related changes in p38 MAP kinase contribute to the decreased steroid production by the adrenocortical cells from old rats. Aging Cell 2008, 7, 168-178.

31. Stocco, D.M.; Wells, J.; Clark, B.J. The effects of hydrogen peroxide on steroidogenesis in mouse Leydig tumor cells. Endocrinology 1993, 133, 2827-2832.

32. Lee, S.Y.; Gong, E.Y.; Hong, C.Y.; Kim, K.H.; Han, J.S.; Ryu, J.C.; Chae, H.Z.; Yun, C.H.; Lee, K. ROS inhibit the expression of testicular steroidogenic enzyme genes via the suppression of Nur77 transactivation. Free Radic. Biol. Med. 2009, 47, 1591-1600.

33. Murugesan, P.; Muthusamy, T.; Balasubramanian, K.; Arunakaran, J. Polychlorinated biphenyl (Aroclor 1254) inhibits testosterone biosynthesis and antioxidant enzymes in cultured rat Leydig cells. Reprod. Toxicol. 2008, 25, 447-454.

34. Wu, L.S.; Chen, J.C.; Sheu, S.Y.; Huang, C.C.; Kuo, Y.H.; Chiu, C.H.; Lian, W.X.; Yang, C.J.; Kaphle, K.; Lin, J.H. Isocupressic acid blocks progesterone production from bovine luteal cells. Am. J. Chin. Med. 2002, 30, 533-541.

35. Guo, I.C.; Wu, L.S.; Lin, J.H.; Chung, B.C. Differential inhibition of progesterone synthesis in bovine luteal cells by estrogens and androgens. Life Sci. 2001, 68, 1851-1865.

36. Chiu, C.H.; Fei, C.Y.; Srinivasan, R.; Wu, L.S. Inhibitory effects of epidermal growth factor on progesterone production of ovarian granulosa cells in Tsaiya duck (Anas platyrhynchos var. domestica). Br. Poult. Sci. 2010, 51, 821-827.

37. Chen, H.; Zhou, L.; Lin, C.Y.; Beattie, M.C.; Liu, J.; Zirkin, B.R. Effect of glutathione redox state on Leydig cell susceptibility to acute oxidative stress. Mol. Cell Endocrinol. 2010, 323, 147-154.

38. Tosca, L.; Crochet, S.; Ferré, P.; Foufelle, F.; Tesseraud, S.; Dupont, J. AMP-activated protein kinase activation modulates progesterone secretion in granulosa cells from hen preovulatory follicles. J. Endocrinol. 2006, 190, 85-97.

39. Chin, C.H.; Wu, L.S.; Jong, D.S. Production and application of a polyclonal peptide antiserum for universal detection of StAR protein. Chin. J. Physiol. 2008, 51, 54-61. 
40. Chiu, C.H.; Wei, H.W.; Wu, L. Generation and utilization of P450 cholesterol side-chain cleavage enzyme and $3 \beta$-hydroxysteroid dehydrogenase antibodies for universal detection. J. Immunoass. 2008, 29, 152-160.

(C) 2015 by the authors; licensee MDPI, Basel, Switzerland. This article is an open access article distributed under the terms and conditions of the Creative Commons Attribution license (http://creativecommons.org/licenses/by/4.0/). 